Article

\title{
Natural Philosophy and the Sciences: Challenging Science's Tunnel Vision
}

\author{
Arran Gare $\mathbb{D}$
}

Philosophy and Cultural Inquiry, School of Arts, Social Science and the Humanities, Swinburne University of Technology, Hawthorn 3122, Victoria, Australia; agare@swin.edu.au; Tel.: +61-3-93703405

Received: 31 August 2018; Accepted: 17 October 2018; Published: 21 October 2018

\begin{abstract}
Prior to the nineteenth century, those who are now regarded as scientists were referred to as natural philosophers. With empiricism, science was claimed to be a superior form of knowledge to philosophy, and natural philosophy was marginalized. This claim for science was challenged by defenders of natural philosophy, and this debate has continued up to the present. The vast majority of mainstream scientists are comfortable in the belief that through applying the scientific method, knowledge will continue to accumulate, and that claims to knowledge outside science apart from practical affairs should not be taken seriously. This is referred to as scientism. It is incumbent on those who defend natural philosophy against scientism not only to expose the illusions and incoherence of scientism, but to show that natural philosophers can make justifiable claims to advancing knowledge. By focusing on a recent characterization and defense of natural philosophy along with a reconstruction of the history of natural philosophy, showing the nature and role of Schelling's conception of dialectical thinking, I will attempt to identify natural philosophy as a coherent tradition of thought and defend it as something different from science and as essential to it, and essential to the broader culture and to civilization.
\end{abstract}

Keywords: natural philosophy; R.M. Unger; L. Smolin; Aristotle; F.W.J. Schelling; Naturphilosophie; A.N. Whitehead; Ivor Leclerc; dialectics

\section{Introduction: The Marginalization of Natural Philosophy}

In a recent book, The Singular Universe and the Reality of Time [1], the legal theorist Roberto Mangabeira Unger and the theoretical physicist Lee Smolin set out to defend the reality of temporal becoming, to incorporate into physics the notion of coevolution, to redefine the nature and role in science of mathematics, and thereby replace basic assumptions deriving from Newton's physics about the nature and role of scientific explanation. However, to do so, they first had to defend natural philosophy, without which, they argued, philosophical assumptions are confused with empirical observations, damaging efforts to advance science in new directions. Natural philosophy no longer exists as a recognized genre, they argued, and '[i]n the absence of an established discourse of natural philosophy, scientists have often used the presentation of ideas to a general educated public as a device by which to address one another with regard to the foundational matters that they cannot readily explore in their technical writings' (p. xvii). They noted that natural philosophy plays a greater role in biology than physics, but even in biology those who engage in natural philosophy are marginalized. Also marginalized are philosophers who have focused on natural philosophy. Instead of masking their arguments as popularizations, Unger and Smolin presented their work explicitly as a contribution to natural philosophy. They then equated natural philosophy to natural history. In the absence of an established discourse of natural philosophy, they had to define what it is, and what is its relation to science. They proclaimed: 
'The discourse of this book is also to be distinguished from the philosophy of science as that discipline is now ordinarily practiced. The work of the philosophy of science is to argue about the meaning, implications, and assumptions of present or past scientific ideas. It offers a view of part of science, from outside or above it, not an intervention within science that seeks to criticize and redirect it.... The proximate matter of the philosophy of science is science. The proximate subject matter of natural philosophy is nature. Unlike the philosophy of science, natural philosophy shares its subject matter with science' (p. xvii).

While Unger and Smolin do provide a good starting point for characterizing natural philosophy and for equating it to natural history, without an established discourse of natural philosophy it is difficult to defend their definition of it and further extend their work. To do this and develop it further, it is necessary to identify what works in the past could be characterized as natural philosophy. Without an established discourse on this, however, it is difficult to even identify which thinkers in the past should be characterized as natural philosophers. What we are faced with is such a disintegration of intellectual traditions that it is necessary to reconstruct the history of natural philosophy and its relation to both philosophy and science in order to judge whether or not Unger and Smolin have correctly specified their subject matter, whether they are making a real contribution to its development, and to characterize and then defend natural philosophy as a valid form of knowledge.

This is more difficult than it might seem because despite the work of philosophically oriented historians of science, most histories of what is taken to be science have ignored natural philosophy as such and thereby distorted these histories. This is evident even in the classification of who was a philosopher and who a scientist. Newton is regarded as a major figure in science and Leibniz a major figure in philosophy, but both were natural philosophers who debated with each other, mostly indirectly in the Leibniz-Clarke Correspondence. Among philosophers, the most important natural philosophers are frequently characterized, and sometimes have characterized themselves, as metaphysicians. This is problematic because when the notion of metaphysics was coined in collecting a number of Aristotle's works together and labelling them as the work which followed writings on physics, that is, Metaphysics, the subject matter of this was confused [2] (ch. vi). Studies of this book have shown that early in his career when Aristotle was still aligned with Plato, the subject of this work was the study of what exists and is unchanging, the Unmoved Movers conceived of as divine beings, and metaphysics came to be identified with theology. On this basis, metaphysics was taken to be a subject dealing with a reality beyond the physical world, that is, nature. Later, Aristotle rejected this as his focus and redefined his goal as the study of being. As he put it:

'There is a science which takes up the theory of being as being and of what 'to be' means, taken by itself. It is identical with none of the sciences whose subjects are defined as special aspects of being. For none of them looks upon being on the whole or generally; but each, isolating some part, gets a view of the whole only incidentally, as do the mathematical sciences. Since we are searching for the first principles and most general factors of being, these must clearly be distinctive traits of some nature.' [3] (p. 61, 1003a21-28).

As John Herman Randall interpreted him, metaphysics so conceived is the study of 'What properties are involved in "being" anything, in any subject matter that can be investigated, in "being as being"?' [2] (p. 110). This is what has come to be called ontology.

Aristotle himself noted that this sense of metaphysics has two aspects [2] (p. 110). One is that 'to be means to be something that can be stated in discourse' [2] (p. 111). This sense of metaphysics has been taken up exclusively in so-called 'analytic metaphysics' in which discourse is identified with symbolic logic and its interpretation [4]. Exemplifying such analytic metaphysics, Willard van Orman Quine wrote, 'To be is to be the value of a variable' [4] (p. 5). This does not have a place for natural philosophy as such, even when as in the case of Quine and his followers, they defend naturalism. In fact, while the work of these analytic metaphysicians can be important for natural philosophy, more commonly, it has crippled it [5] (ch. 2). The second aspect of Aristotle's metaphysics in this 
sense is the examination of what comes into being and passes away, with the 'essence' of any such entity being what is knowable and stateable about it. This is natural philosophy. Later, Aristotle modified this characterization of metaphysics as natural philosophy to incorporate the eternal features of the celestial realm. Such an investigation requires an account of the stuff of which everything is made, the growth process, and the internal organizational principle, thereby showing what is it to explain anything, the place of principles and consideration of the status and role of mathematics in this. Natural philosophy also includes the quest to specify the main kinds of beings that are possible and that exist and their relation to each other; most importantly, physical beings as such, including those that are not alive, living beings and the different kinds of these, including humans, and then abstract entities such as mathematical relations. Living beings were investigated by Aristotle in De Anima, and this should be seen, along with Metaphysics, On Generation and Corruption and several other works, as a major contribution to natural philosophy. A number of philosophers characterized as metaphysicians, along with philosophical biologists and philosophical anthropologists, are centrally engaged in natural philosophy in this sense, and their work is central to the tradition of natural philosophy, but none of these are not identified as natural philosophers by simply being labelled as metaphysicians.

Understanding the history of metaphysics as natural philosophy, ignoring other forms of metaphysics, does identify natural philosophy as a tradition of thought, however. As Aristotle himself argued, this tradition began with philosophy itself. As he put it, 'the question that has always been asked and is still being asked today, the ever-puzzling question "What is being?" amounts to this, “What is primary being (ousia)?' [3] (p. 131, 1028b). He characterized efforts to answer this question as first philosophy because this is basic to all particular sciences. These deal with particular kinds of being and the primary principles and factors basic to them, but first philosophy deals with what is basic to all sciences [3] (p. 63, 1004a). It is also the prime focus of the philosopher since the task of the philosopher is to view things in a total way, and this is achieved by characterizing what is primary being [3] (p. 64, 1004b).

What Aristotle understood this question to mean and how it could be answered is clarified by the first book of his Metaphysics where he discusses his predecessors. For naturalists such as the first philosophers, Thales, Anaximander, and Anaximenes, natural philosophy was identical with metaphysics, with Thales claiming that primary being is water, Anaximander that it is the limiting of the unlimited, and Anaximenes that it is air. The atomists argued that it is atoms and the void. Their treatises were, according to Aristotle, peri physeōs 'concerning nature'. They were concerned with the nature of physical existence, or physis, the term that the Latins translated as natura. In examining these philosophers, Aristotle recounted what they claimed primary being to be, and then how the principles of this were used to explain all else. That is, the task of philosophy for naturalists is not only to define what nature (or physis) is as primary being, but to show how everything else can be explained as an aspect or manifestation or as having been generated by this primary being. If this is to be carried through, it must include nature before the existence of life or humans (Anaximander had offered a theory of evolution in which the unlimited engendered all particular entities, and life evolved in the oceans and then colonized land), and also humans with their philosophical discourse about nature, and along with this, discourse about philosophical discourse.

Aristotle also showed the importance of identifying the tradition of metaphysics as natural philosophy and writing its history, since the conclusions he reached and the defense of these conclusions involved identifying his predecessors, and then criticizing and claiming to overcome what he then claimed to have shown were the limitations of their philosophies.

Such philosophical discourse can include the claims about and avowed beliefs of philosophers in non-natural entities, along with abstract thoughts and non-existent imaginary beings. This means that naturalists can accept that natural philosophy also includes a place for questioning naturalism and claiming that there is more to philosophy than natural philosophy. For naturalists, such questioning 
and such claims will also be seen as products of nature, that is, products of beings which have been generated by and are part of nature.

For those who reject naturalism, there is still a place for natural philosophy, although such philosophers claim there are realities, entities, or possibly non-entities that are beyond nature. These can be mathematical forms, relations or truths, other Platonic forms, immortal souls or transcendent divine beings who can be conceived of as having created nature or as the beings from which nature emanated, as in Plotinus. Philosophy for non-naturalists is broader than it is for naturalists, but should include natural philosophy as one of its major domains of inquiry, unless as extreme Idealists they completely deny the reality of nature; but then even this is a form of natural philosophy.

Subsequently, almost all work in natural philosophy has taken Aristotle's third characterization of metaphysics as the quest to characterize primary being, through which everything else can be understood, as a reference point for defining and advancing such work. Usually, but not always, this goes along with utilizing Aristotle's arguments and ideas in his own philosophy of nature. This is true not only of those who embraced Aristotle's own characterization of metaphysics and natural philosophy along with his work in natural philosophy, but also those who have rejected both these and developed alternatives, often attempting to revive the philosophies of nature criticized by Aristotle. This was the case with the Stoics and Neoplatonists, medieval Christian philosophers and the natural philosophers of the fourteenth century. It was also the case with natural philosophers associated with the scientific revolution of the seventeenth century, where atomism was revived and entelechies excluded from the physical world. Aristotle's own work was not entirely rejected by those claiming to be scientists, however, as is evident from efforts to revive aspects of it, such as the notion of final causes by Hans Driesch, theoretical biologists developing the concept of biofields and chreods, the mathematician René Thom (who coined the term 'attractor' for precisely this reason), Robert Rosen, Stanley Salthe, biosemioticians, Terrence Deacon and Robert Ulanowicz, among others. The living presence of Aristotle's philosophy is also evident in efforts to revive aspects of his notion of mathematics as a realm of abstractions rather than primary beings, in opposition to the widespread assumption by physicists and mathematicians of Pythagorean Platonism.

The importance of natural philosophy as the whole or major part of metaphysics was revealed in the twentieth century by historians of science, beginning with their study of the seventeenth century scientific revolution. Émile Meyerson, Ernst Cassirer, Gaston Bachelard, Edwin A. Burtt, Alexandre Koyré, Karl Popper, Michael Polanyi, Norwood Russell Hanson, Stephen Toulmin, Thomas Kuhn, Imré Lakatos, and Paul Feyerabend were only the most prominent of the historians of science and historical-oriented philosophers of science involved in refuting the claims of the empiricists, positivists, and logical positivists who had defined science in opposition to metaphysics. Their work demonstrated the essential role of natural philosophy to science (although usually characterized as metaphysics rather than as natural philosophy), and the central importance of work in natural philosophy when major new directions in science have been taken, as opposed to the claims of the logical positivists who dismissed natural philosophy as metaphysics, a speculative discourse that they claimed should be superseded by science and the rigorous application of the scientific method based on empirical work.

These historians-philosophers also exposed the characterizations of subsequent science by empiricists, positivists, and logical positivists, essentially, the bucket image of science (as Karl Popper called it) according to which science accumulates certain knowledge by engaging in empirical investigation rather than speculation, to be fallacious. Most of what are now recognized as the most important advances in science have been shown to be the result of theoretical work and, more fundamentally, work in natural philosophy struggling with theoretical and philosophical problems, using imaginative thought experiments rather than empirical work. Far from science leaving metaphysics behind, what defines genuine science is the effort to advance our comprehension of the world in terms of some well worked-out philosophy of nature; that is, a metaphysical doctrine. For instance, Newton's greatest achievement was to have shown that Johannes Kepler's explanation of the observations by Tycho Brahe of the movement of the planets, that they were in elliptical orbits 
around the sun, could in turn be explained (at least in the case of Mars) through the postulation of a gravitational force decreasing with the square of distance, along with his three laws of motion. This required the development of a new form of mathematics, calculus, and its defense. However, this theory required a fundamental revision and a new synthesis of the notions of space, time, motion, acceleration, and matter, that is, a philosophy of nature. This synthesis was strongly influenced by the Cambridge Neoplatonists as well as Bruno, Gassendi, Descartes, and Boyle. However, his philosophy of nature was a new synthesis and was defended in opposition to not only Aristotelian natural philosophy but also to the philosophies of his immediate predecessors. [6] Newton's success entrenched his natural philosophy as the basis for most of what came to be identified as science for more than a century. As Kant pointed out, working in the shadow of Newton, we do not simply receive experience but make observational judgements on the basis of questions we formulate using concepts. In Newtonian science, these questions are formulated through the categories or conceptual framework of Newtonian natural philosophy.

Newton did engage in empirical work in his effort to convert base metals into gold using mercury. Here he worked with the poorly worked-out natural philosophy of the alchemists without questioning it, asking questions of nature that could not be answered, and achieved nothing, apart from suffering the effects of mercury poisoning.

\section{The Failure to Revivify Natural Philosophy in the Late Twentieth Century}

Such historical work should have been expected to and did stimulate some new work in natural philosophy, with Meyerson, Bachelard, Polanyi, Popper, and Feyerabend making contributions to this. Some of this work also helped stimulate the revival of interest in the work of late Nineteenth and early twentieth century philosophers such as C.S. Peirce, Henri Bergson, and Alfred North Whitehead, who, as natural philosophers, had been marginalized and often misrepresented after the rise of analytic philosophy. Such work also helped inspire efforts to combat the influence of logical positivism in science itself and to make sense of and advance the revolutions in thought that had taken place or were taking place over the last century in the way nature was understood. It became very clear that the opposition between Albert Einstein and Niels Bohr was not over empirical work, or even theory, but their fundamentally different philosophies of nature. However, even in the philosophy of science, natural philosophy was very marginal to the direction of research subsequently taken by most philosophers, and science itself has been and continues to be damaged through the influence of the false view of science promulgated by empiricists, positivists, and logical positivists. This is evident in the current crisis in physics with its preoccupation with mathematics unrelated to any coherent natural philosophy [7].

Work on the history of science did create a supportive environment for physicists and theoretical biologists to openly proclaim their ideas on natural philosophy, but as Unger and Smolin observed, almost always these were in popularizations of their work rather than being part of mainstream academic discourse. Or they were in anthologies which were generally ignored. It also influenced some philosophers, although these were rare.

For instance, it helped revive philosophical biology and philosophy anthropology, stimulating interest in earlier work on these topics by phenomenologists such as Max Scheler. These philosophers had opposed not only the mechanistic world-view and the Hobbesian conception of humans based on this, but the Idealist turn taken by Edmund Husserl. Marjorie Grene, who aligned herself with Polanyi, played a leading role in the temporary revival of these subjects [8]. As suggested, philosophical biology and philosophical anthropology should be seen as important components of natural philosophy. The quest to revive philosophical biology has been associated with efforts to support more radical developments within science challenging the usual epistemological and ontological reductionism [9]. In France, where logical positivism had little influence and phenomenology had a major impact, the historical work of Bachelard and Koyré helped stimulate Maurice Merleau-Ponty's redirection of his phenomenological philosophy in the 1950s to build on his work in philosophical anthropology and 
philosophical biology to embrace and advance natural philosophy generally. Merleau-Ponty returned to the whole tradition of natural philosophy, examining the work of Friedrich Schelling, Bergson, and Whitehead, and recent advances in physics along with theoretical biology. Unfortunately, he died before developing these ideas, and the contents of his lectures were only published in 1995 in French (and 2003 in English translation [10]). French philosophy took a very different path and abandoned the trajectory of Merleau-Ponty's thought. However, his work inspired later efforts by Francisco Varela, Evan Thompson and others to 'naturalize' phenomenology [11-13], and this has become a major movement of thought that is advancing natural philosophy, but again still as a marginal philosophical and scientific movement.

In Britain, beginning in the 1970s, Rom Harré embraced the rejection of logical positivism but criticized the anti-realist tendencies in Kuhn's characterization of science and defended a form of metaphorical realism that made natural philosophy central to his work [14]. Focusing on chemistry rather than physics to begin with, his argument against logical positivism and neo-Kantianism was that the regularities expressed in scientific laws must be explained as manifestations of the essential properties of entities, their powers and liabilities, the dormitive powers of opium for instance, which in turn must be explained through the powers and liabilities of their components. In doing so, he drew a distinction between logical necessity associated with deduction and natural necessity associated with causal processes. Reviving interest in the work of Roger Boscovich who in A theory of Natural Philosophy had attempted to reconcile Leibniz and Newton by proposing and developing a dynamic theory of matter, Harré, along with E.H. Madden, developed ideas on causal powers and fields as fields of possibilities. This work had a significant influence on some scientists, and building on this work, Harré attempted to provide new foundations for psychology which was essentially work in philosophical anthropology [15-17]. Although aspects of Harré's naturalism were defended and developed by Roy Bhaskar, this work was largely ignored by philosophers, although it did have some influence on psychologists.

More success was achieved in developing natural philosophy by philosophers who aligned themselves explicitly with specific natural philosophers of the past who had been marginalized by the development of analytic philosophy, although this had the effect of creating intellectual ghettoes of their work, ignored by mainstream philosophers. Those aligned with Alfred North Whitehead, mostly in the USA but also in Belgium and elsewhere, formed the biggest group in this regard, and in so doing, succeeded in attracting and offering support for radical scientists, including David Bohm, Ilya Prigogine, Joseph Early and later, the quantum physicist Henry Stapp and the theoretical ecologist Robert Ulanowicz. Gilles Deleuze (who was strongly influenced by Leibniz and Bergson) in his later years also embraced aspects of Whitehead's philosophy. This Whiteheadian movement also provided support for philosophers striving to keep alive and further develop the contributions to natural philosophy of Henri Bergson and C.S. Peirce and this led to further efforts to revive natural philosophy. Milič Čapek defended and further developed Bergson's philosophy as a major contribution to the theory of time and space, showing its relevance for interpreting recent work in physics and, more broadly, defending the value of such philosophical work [18]. His work has been ignored even by later Bergsonian philosophers.

Other natural philosophers influenced by these thinkers such as Suzanne Langer, Dorothy Emmet, Ivor Leclerc, Frederick Ferré, John A. Jungerman, and Michel Weber have attempted to advance natural philosophy in new directions. From the perspective of these attempting to revive natural philosophy, the most important of these is Ivor Leclerc.

Leclerc began as an interpreter of the philosophy of Whitehead. Arguing that Whitehead should be seen as part of the tradition of natural philosophy rather than merely an interpreter and philosopher of science, re-examining the philosophies of nature that had been put in place in the seventeenth century, his work should be interpreted as an argument that these had been rendered obsolete and were now hindering the advance of science [19]. His work should then be understood as an effort to supply a new philosophy of nature. On this assumption, Leclerc attempted to overcome not only what 
he took to be the limitations of the natural philosophy inherited from the seventeenth century, but also of Whitehead's philosophy of nature. Leclerc later concluded that Aristotle and Leibniz were just as important for natural philosophy as Whitehead, and from this perspective revisited the problems they had addressed. In doing so, he provided a history of natural philosophy up to the seventeenth century, revealing its achievements and failures and offering a thorough critique of the seventeenth century natural philosophers, including both Descartes and Newton. He also went on to criticize Kant's natural philosophy. Leclerc then offered his own work as a revival of natural philosophy and a further contribution to the tradition of natural philosophy $[20,21]$. He concluded his major work, The Nature of Physical Existence, published in 1972 with the proclamation:

'... as in the seventeenth century, 'the philosophy of nature' must not only be brought into the forefront, but the recognition of its intrinsic relevance to and need by the scientific enterprise must be restored. Then it will be seen that there are not two independent enterprises, science and philosophy, but one, the inquiry into nature, having two complementary and mutually dependent aspects' [20] (p. 351).

Leclerc found great resistance to this proposal, and offered an explanation for it very similar to that of Unger and Smolin. As he put it in his later book The Philosophy of Nature published in 1986,

'Until about two centuries ago, there had been a main field of inquiry known as philosophia naturalis, the philosophy of nature. Then this field of inquiry fairly abruptly ceased being pursued. It is interesting, and as I shall show, important for us today to determine how and why this happened.... After Newton the success of the new natural science had become overwhelming ... [T] he universe was divided into two, one part consisting of matter, constituting nature, and the other part consisting of mind or spirit. The fields of inquiry were divided accordingly: natural science ruled in the realm of nature, and philosophy in the realm of mind. Thenceforth these two, science and philosophy, each went their own way, in separation from the other. In this division, there was no place for the philosophy of nature. Its object had been nature, and this was now assigned to natural science. What remained of philosophy was only epistemological and logical inquiry, which has natural science, but not nature, as its object-today, usually called the philosophy of science. Philosophy of nature as a field of inquiry ceased to exist' [21] (p. 3f.).

Leclerc argued that the advances in the sciences beyond the philosophy of nature promulgated and adopted in the seventeenth century had left modern civilization without any philosophy of nature, a condition that must be overcome not only in the interests of advancing science, but more importantly, for the broader culture.

His efforts to revive natural philosophy also failed, although he did have an influence on the Nobel Laureate in chemistry, Ilya Prigogine, and other eminent scientists, who also made significant contributions to natural philosophy [22-24].

A later effort to extend and defend process metaphysics by the prominent analytic philosopher, Nicholas Rescher [25], who had been influenced by Peirce, also had little influence other than on philosophers who had already aligned themselves with natural philosophy [26].

As Unger and Smolin noted, natural philosophy had more success in biology where theoretical biologists set out to challenge the reductionism of mainstream biology and evolutionary theory. There is no sharp dividing line between theoretical biology and philosophical biology and works devoted to theoretical biology were clearly significant contributions to philosophical biology and natural philosophy generally. This was the case with Ludwig von Bertalanffy who founded general systems theory which had a major influence on a whole range of disciplines, although largely ignored in philosophy. The conferences on theoretical biology in Switzerland organized by the British biologist C.H. Waddington in the late 1960s and early 1970s, issuing in the four-volume work Toward a Theoretical Biology [27], contained strong defenses of metaphysics as natural philosophy by Waddington and David 
Bohm, with further developments in natural philosophy emerging from discussions. Participants in these conferences, which included David Bohm, Brian Goodwin, Richard Lewontin, Richard Levins, Stuart Kauffman, and Howard Pattee, subsequently wrote major works which contributed further to natural philosophy, much of it associated with interpreting and developing complexity theory. Pattee was particularly important in this regard, having developed a theory of hierarchical order and emergence through new constraints, an idea that was further developed by the theoretical ecologist, Timothy Allen, and the theoretical biologist, Stan Salthe [28-30], and was later taken up by the biosemioticians [31].

Whitehead was the natural philosopher most commonly invoked at these conferences on theoretical biology. Independently of these theoretical biologists, the Whiteheadian philosophers John Cobb Jr. and David Ray Griffin organized another conference on the philosophy of biology in USA, which was published in 1978 as Mind in Nature [32]. This was followed by a series of conferences organized by the Center for Process Studies in USA, issuing in several books on natural philosophy [33-35]. All such work, along with the work of the Whitehead-inspired natural philosophers Langer, Emmet, Ferré, Jungerman, and Weber, is ignored by all but a minority of philosophers who hold academic positions in philosophy departments, particularly in Anglophone countries, and has been taken more seriously by theology departments and by scientists.

Largely independently of this Whiteheadian movement, biosemioticians took up the work of Peirce and embraced his radical ideas on natural philosophy. In doing so, they helped bring into prominence the few interpreters of Peirce who had taken seriously and argued for the importance of this aspect of Peirce's work. The biosemioticians are still striving to develop their alternative approach to biology and to draw out the broader implications of Peircian semiotics [36]. Their views have been strengthened by building on systems theory and interpreting biosemiotics through hierarchy theory as put forward by Pattee (who was developing ideas from Michael Polanyi), originally by Stanley Salthe [28-30] who has been a strong supporter of natural philosophy. Inspired by biosemiotics, Søren Brier has set out to construct a whole philosophy of nature based on the notion of cybersemiotics [37]. Largely through the efforts of the biologists Jesper Hoffmeyer and Kalevi Kull, biosemioticians have established strongholds in Denmark and Estonia, but globally they are still a marginalized group and all but ignored in philosophy, at least outside Denmark.

Within the discipline of philosophy itself, proponents of natural philosophy have been scattered and isolated, usually occupying positions in lower-ranked universities or working as private scholars with little influence and often having to deal with hostile intellectual, institutional, and political environments. Denmark appears to be an exception. Apart from important works in biosemiotics, three major works in natural philosophy were published in Denmark around the turn of the millennium, Nature and Lifeworld [38] edited by Bengt-Pedersen and Thomassen, Downward Causation [39] edited by Andersen, Emmeche, Finnemann, and Christensen, and Process Theories [40] edited by Johanna Seibt. However, this is unusual. Generally, academic philosophers do not recognize natural philosophy or the philosophy of nature as part of contemporary philosophy.

So, it appears from this survey that Unger and Smolin are right to claim that there is no widely accepted discourse on natural philosophy at present, and they are right in their suggestion that the most influential work in natural philosophy has been developed and presented in popularizations of science by scientists; however, this survey shows that there are a number of marginalized and thereby fragmentary discourses on natural philosophy that have kept the subject alive. The problem is that they are so marginalized and fragmentary at present that they fail to cohere as an established discourse based on a coherent tradition. While scientists engaging in natural philosophy, as with Unger and Smolin, acknowledge predecessors, generally they do not really engage with their work, and so there is no way in which what is presented can be judged to be real progress in natural philosophy itself. Furthermore, popularizations by scientists are directed to an intelligent general audience which appears to be disappearing with the eclipse of print media. Young people read far less books, and such works are seldom studied in universities. Failing to constitute a coherent tradition, the proponents 
of natural philosophy have failed to uproot the deep assumptions about nature and what counts as science put in place by the seventeenth century scientific revolution. However, identifying these fragments and putting them together in an historical narrative could have the potential to reconstitute natural philosophy as a coherent tradition and provide a context and discourse in which there could be real progress. Here I will defend this claim, constructing such a narrative both using and defending a dialectical form of reasoning, and in so doing, identifying and integrating a Schellingian tradition of natural philosophy through which the work of Unger and Smolin can be interpreted and evaluated as a contribution to this Schellingian tradition.

\section{The Challenge of Advancing Natural Philosophy}

As Unger and Smolin suggest, without natural philosophy to bring into question current manifestly defective assumptions, major advances in science are blocked by deficiencies in entrenched assumptions. As I have noted, this has been well demonstrated by historians of science, historically oriented philosophers of science, and a number of radical scientists. This is likely to be even more the case when the natural philosophy assumed within mainstream science has entrenched itself not only in science, but in the broader culture which then controls how science is funded and developed. What we have at present is funding bodies identifying science with nothing but empirical research and valuing it only insofar as it facilitates the development of profitable technology. Such efforts to control science by governments can be even more problematic to the broader culture. It can block efforts of societies to face up to their problems and deal with them, which is clearly the case with the inadequate response of societies today to deal adequately with ecological destruction. If this is the case, then it is vital to the future of civilization that proponents of natural philosophy work out how to identify the causes of past failures to revive natural philosophy and overcome these failures [41].

The most important reason for the failure by proponents of natural philosophy to revive it is their failure to adequately specify the difference between natural philosophy and science, and then to justify natural philosophy as a form of knowledge different from science, although essential to it, with a form of reasoning whereby it can be advanced. This is not to say that efforts have not been made in this regard. The problem is to show why these efforts failed, before offering something new.

Since Whitehead is the most influential of the modern natural philosophers of the last century, his efforts to defend speculative philosophy (which for him was essentially 'natural philosophy') can be taken as a point of departure. Whitehead briefly distinguished speculative philosophy from science (and from analytic philosophy) in the epilogue to Modes of Thought. This is very succinct, and bears quoting:

Philosophy is an attitude of mind towards doctrines ignorantly entertained.... The philosophical attempt takes every word, and every phrase, in the verbal expression of thought, and asks, What does it mean? ... Of course you have to start somewhere for the purpose of discourse. But the philosopher, as he argues from his premises, has already marked down every word and phrase in them as topics for future enquiry. No philosopher is satisfied with the concurrence of sensible people, whether they be his colleagues, or even his own previous self. He is always assaulting the boundaries of finitude...

The scientist is also enlarging knowledge. He starts with a group of primitive notions and of primitive relations between these notions, which defines the scope of his science.... [T]he scientist and the philosopher face in opposite directions. The scientist asks for the consequences, and seeks to observe the realization of such consequences in the universe. The philosopher asks for the meaning of these ideas in terms of the welter of characterizations which infest the world [42] (p. 171f.).

Here Whitehead made the crucial point that the philosopher and the scientist face in opposite directions even when dealing with the same subject matter. Their interests are different. Scientists 
as scientists (that is, when not reflecting philosophically on their research) work with assumptions, usually unexamined, which direct their research and define their goals, with their focus being on particular, very specific objects, situations, or problems. This is not necessarily empirical research; it is very often theoretical research provoked by contradictions between different branches of science, as when Einstein struggled to deal with the incompatibility between Newtonian physics and Maxwell's theory of electro-magnetic fields. It can also be mathematical problems, and the problem of developing and utilizing appropriate forms of mathematics, as was the case with Newton, Maxwell, and Einstein. The concern of scientists is to achieve as much certainty as possible in their conclusions by the rigor with which they apply their methods, reconcile inconsistencies or spell the implications of their theories, devise experiments where predictions can be validated, or make the required observations. While Einstein did not engage in empirical work, he was concerned to make precise predictions from his theories which could be observed. Within science there is therefore a tendency to increasing specialization to achieve such certainty, resulting in the multiplication of disciplines and subdisciplines, often without much concern for their relationship to each other. Consequently, scientific knowledge tends to become compartmentalized. This can marginalize theoretical scientists whose main interest is in overcoming inconsistencies between different branches of science. This tendency has become so extreme over the last fifty years that, as Bruce Charlton argued in Not even trying ... The Corruption of Real Science, disciplines no longer check each other, making defective assumptions invisible and ineradicable. We no longer have 'Science' as such, but 'an arbitrary collection, a loose heap of micro-specialties each yielding autonomous micro-knowledge of unknowable applicability' [43] (p. 121).

The natural philosopher on the other hand has a global focus and must be prepared to question every assumption, and when investigating any particular object or subject matter, is concerned to understand how these relate to everything else that could be investigated. The assumption that they are so related, that no entity can be conceived in complete abstraction from everything else, Whitehead suggested is the great preservative of rationalistic sanity. It is equivalent to C.S. Peirce's notion of synechism, that the universe exists as a continuous whole of all its parts, with no part being fully separate. Consequently, natural philosophers are concerned with how all the different disciplines and arts are related to each other and must engage not only with the assumptions underpinning scientific disciplines, but the assumptions dominating other forms of inquiry and the broader culture while continuously questioning their own assumptions. They are less focused on consistency between sharply defined concepts than with inclusivity, being prepared to work with relatively vague concepts to achieve this. As with theoretical science, this involves considering whether knowledge claims made in diverse fields of practice or inquiry are consistent with or contradict each other, and then how to overcome these contradictions, but over a much broader range of scientific and cultural domains. Einstein as a theoretical scientist, for instance, paid little attention to whether his theories were compatible with the existence of conscious beings capable of taking responsibility for their actions, creating civilizations and developing scientific theories, while this was the central concern of Whitehead as a natural philosopher.

Whitehead seemed to assume that the philosopher and the scientist are different people, but this need not be the case, and prior to the eighteenth century, seldom was the case. Those studying nature were usually both philosophers and scientists as these were characterized by Whitehead. Natural philosophy is broader than theoretical work in science, having to consider and give a place to nature in all the diverse ways that nature is experienced. While this includes what is experienced in everyday practical life, in history and in the arts: sculpture, painting, architecture, and poetry as well as the sciences, advances of science cannot be ignored. It is for this reason, as Unger and Smolin pointed out, that most of the most important work in natural philosophy in recent years has been undertaken by investigators who could also be called scientists, although only a few scientists now are also natural philosophers. Whitehead and Peirce exemplified this duality, each being natural philosophers after having advanced mathematics and participated in scientific work. Generally, it is those scientists involved in what Thomas Kuhn called revolutionary science who tend to be natural philosophers as 
well as being scientists. That is, they are not prepared to accept received assumptions and are oriented to achieving a comprehensive understanding of the world, including themselves as part of the world, while being engaged in one or more specialized areas of scientific research.

There is also an asymmetry in natural philosophy and science as characterized by Whitehead because science as it has developed since the seventeenth century would not have been possible without the work of natural philosophers, while natural philosophy existed before science. This does not mean that there are not people who think they can ignore theory and make observations and measurements and look for correlations using usually crude forms of statistics, and then call their work science. This often happens in psychology, sociology, and medicine. This is widely recognized as pseudo-science. However, it is still assumed by most philosophers and scientists who are doing genuine science that once science is established, it can leave philosophy behind. Even Kuhn was more sympathetic to what he called normal science, where philosophical questions have been settled, than revolutionary science. This view was neatly summarized by the editors of After Philosophy: End or Transformation when they wrote: 'The rise of the modern sciences of nature removed-forever, it seems-vast domains from the authority of philosophical reflection', and '[ $t$ ]he ensuing turn to the subject, appears now to have been only a temporary stopgap, which could remain effective only until the human sciences and the arts grew strong enough to claim their proper domains from philosophy as well' [44] (p. 1).

This view had already been challenged by Whitehead. As he argued:

'The Certainties of Science are a delusion. They are hedged around with unexplored limitations. Our handling of scientific doctrines is controlled by the diffused metaphysical concepts of our epoch. Even so, we are continually led into errors of expectation. Also, whenever some new mode of observational experience is obtained the old doctrines crumble into a fog of inaccuracies' [45] (p. 154).

If science is not to stagnate, he went on to argue, its assumptions must be open to question by philosophers concerned to spell out the implications of ideas in each domain of enquiry for every other domain. As he put it:

'[O]ne aim of philosophy is to challenge the half-truths constituting the scientific first principles. The systematization of knowledge cannot be conducted in watertight compartments. All general truths condition each other; and the limits of their application cannot be adequately defined apart from their correlation by yet wider generalities. The criticism of principles must chiefly take the form of determining the proper meanings of the notions of the various sciences, when these notions are considered in respect to their status relatively to each other. The determination of this status requires a generality transcending any special subject-matter' [46] (p. 10).

This very much accords with the arguments of Unger and Smolin for natural philosophy.

There has to be more than this, though. Normal scientists take for granted the conditions for their operation, including language, institutions, traditions, and cultural fields with their long histories. All of these must be acknowledged by natural philosophers who, in their commitment to comprehensiveness, must acknowledge that their work is being undertaken in a world of which they are part, and which is already underway. Normal scientists applying their methods can ignore the ultimate incoherencies of the natural philosophy they assume. This is clearly the case with those working with various forms of reductionism, most of which have their roots in the seventeenth century scientific revolution. The natural philosophies which came to prevail at this time, whether Cartesian or Newtonian, provided strong support for the experimental methods associated with methodological reductionism developed by Francis Bacon and refined by Galileo, where boundary conditions were set up to enable variables to be correlated to make measurable and testable predictions. However, their conceptions of nature made it impossible to understand how there could be conscious, 
self-reflective beings with their culture, institutions, and capacity to ask questions and act according to plans who could investigate, set up experiments and comprehend nature so conceived. Natural philosophy, being obliged to deal with every subject matter, must be able to account for the possibility of there being natural philosophers and scientists as subjects, along with their institutions, being able to gain such knowledge. For this reason, the scientific achievements generated by the seventeenth century scientific revolution have always been problematic from the perspective of subsequent natural philosophy and this has been the central problem for natural philosophers from Spinoza and Leibniz onward.

Even if natural philosophy can be shown to be essential to science and culture generally, there is a problem of how to evaluate rational progress in its development. While normal science can proceed with relatively clear criteria of what counts as advances in knowledge, natural philosophy brings all criteria into question. This means that radically new developments in natural philosophy, along with the new forms of science they inspire, are left without criteria to evaluate them. This is the problem that Kuhn had to confront in accounting for claims to progress with revolutionary science. Whitehead did attempt to provide general criteria for evaluating philosophies. As he put it in Process and Reality:

'Speculative Philosophy is the endeavour to frame a coherent, logical, necessary system of general ideas in terms of which every element of our experience can be interpreted. By this notion of 'interpretation' I mean that everything of which we are conscious, as enjoyed, perceived, willed, or thought, shall have the character of a particular instance of the general scheme. Thus the philosophical scheme should be coherent, logical, and in respect of interpretation, applicable and adequate. Here 'applicable' means that some items of experience are thus interpretable, and 'adequate' means that there are no items incapable of such interpretation' [46] (p. 3).

These notions are vague when it comes to utilizing them in practice, however, and Whitehead at one stage claimed that when it comes to speculative philosophy, there is no method. As he put it:

'The speculative Reason is in its essence untrammeled by method. Its function is to pierce into the general reasons beyond limited reasons, to understand all methods as coordinated in a nature of things only to be grasped by transcending all method. This infinite ideal is never to be attained by the bounded intelligence of mankind' [47] (p. 51).

Consequently, there can be no absolute criteria of success, and no philosophical system can ever be entirely successful.

However, Whitehead qualified this conclusion, arguing that there is a method of sorts involved in reaching beyond set bounds, including all existing methods. It was this 'method' which was discovered by the Greeks, and why we now talk of speculative reason rather than inspiration. Essentially, speculative reason is, in the terminology of Peirce, abduction, the development of a working hypothesis through the free play of imagination to elucidate experience. Working hypotheses are arrived at through the generalization of patterns experienced in particular domains. This procedure is referred to by Whitehead as the method of 'descriptive generalization', meaning 'the utilization of specific notions, applying to a restricted group of facts, for the divination of the generic notions which apply to all facts' [46] (pp. 5 \& 10). Although Whitehead seldom used the terms, this is a matter of elaborating analogies or metaphors.

Whitehead concluded that what is required to reveal the limitations of each speculative scheme of ideas is a plurality of such schemes, each revealing the limitations of each other [45] (145). But how could these rival systems, each with their own criteria of success, be evaluated in relation to each other? Only by revealing and transcending the limitations of earlier thinkers, while appreciating their achievements. As Christoph Kann in a recent anthology on Whitehead's late work interpreted Whitehead's views on this: 
Any cosmology must be capable of interpreting its predecessors and of expressing their explanatory limitations. In their historical interdependence cosmological conceptions reveal a continuity that protects them from arbitrariness and supports their mutual relevance and their capability of illuminating one another [48] (p. 33).

Alasdair MacIntyre's argument that it is through narratives that judgements can be made in these circumstances provides support for this claim and explains the role of narrative in achieving this. He illustrated this using the work of Galileo as an example:

Wherein lies the superiority of Galileo to his predecessors? The answer is that he, for the first time, enables the work of all his predecessors to be evaluated by a common set of standards. The contributions of Plato, Aristotle, the scholars at Merton College, Oxford and Padua, the work of Copernicus himself at last all fall into place. Or to put matters in another and equivalent way: the history of late medieval science can finally be cast into a coherent narrative.... What the scientific genius, such as Galileo, achieves in his transitions, then, is not only a new way of understanding nature, but also and inseparably a new way of understanding the old sciences way of understanding... It is from the stand-point of the new science that the continuities of narrative history are re-established [49], (pp. 459-460 \& 467).

While it is impossible for any intellectual endeavor to proceed without such a narrative, this must be central to natural philosophy. Aristotle's Metaphysics began with such an historical narrative, the source of most of our knowledge of the early Greek philosophers, and Whitehead in Science and the Modern World [50] provided a brilliant history of modern thought. Even Descartes, who claimed to be starting afresh and beginning his philosophy from supposedly indubitable foundations, could only defend what he was doing through an historical narrative. And it is for this reason that much of the work in natural philosophy since the 1950s, after analytic philosophy and logical positivism had produced a collective amnesia about the history of natural philosophy, has been devoted to history, recovering this lost narrative. But then it is necessary for natural philosophy to characterize and account for narratives and the beings that can produce and understand narratives and be oriented by them.

There is also thinking even more primordial than narratives. To be able to tell stories and have them understood, let alone deploy abstract concepts to particular cases or situations, people need to be able to make discriminations and put the topics they are focusing on in context. It is for this reason that various thinkers have suggested the need for a non-propositional logic of context-dependent discrimination and association. This is the case with Chris Clarke, a theoretical physicist who has also become a natural philosopher. Clarke [51] (p. 83ff.) has invoked the logic of Ignacio Matte Blanco. Another natural philosopher, Joseph Brenner, has attempted to revive the non-Aristotelian ontological logic of the Franco-Romanian thinker, Stéphane Lupasco, based on the inherent dialectics of energy which could serve this function in a more profound way [52]. It is through the implicit utilization of a logic of context and discrimination, allowing for the possibility that entities are inseparable yet essentially opposed to each other, that not only natural philosophy generally, but philosophical biology and philosophical anthropology are able to make contributions to knowledge over and above what is offered by theoretical biology and theoretical psychology or anthropology. These domains of inquiry can and do consider far more than science of what is experienced in recognizing something as alive as opposed to all that is not alive, or in recognizing the distinctive features of humans as opposed to all other living beings. It is for this reason that ultimately, theoretical biology and theoretical anthropology must defer to philosophical biology and philosophical anthropology [53].

\section{Reviving Dialectics}

Considering all this together, it should be evident that the reasoning associated with natural philosophy cannot be reduced to induction and deduction which, logical positivists claimed, were the 
only valid forms of reasoning and the ultimate foundations of scientific knowledge. And as Paul Livingston showed, a great deal of modern analytic philosophy is devoted to dealing with the paradoxes generated by efforts to define reason in these terms, ultimately, unsuccessfully [54] (p. 20ff.). Russell's paradox and Gödel's two incompleteness theorems were just the beginning of these paradoxes, but the most fundamental and insoluble paradox is the incoherence of the claim that deduction and induction exhaust what is involved in reasoning. If this were the case, there would be no way to validate this claim, since it clearly cannot be defended by either induction or deduction or any combination of the two, and so cannot be judged to be true. It is self-refuting. This paradox also highlights the core problem of dealing with reflexivity when attempting to achieve absolute certainty by claiming absolute foundations for reasoning and knowledge.

Natural philosophy is advanced through dialectical reasoning (which at the very minimum includes abduction as well as induction and deduction) and such reasoning must be recognized as more primordial than the demonstrative logic of Aristotle, and even more primordial than modern symbolic logic. These should be seen as adjuncts to dialectical reasoning, which is required to judge when these latter forms of logic are applicable, what are their boundaries of validity, and how to deploy them. The problem here is to characterize dialectical reasoning and thereby to situate, interpret, and defend Whitehead's defense of speculative philosophy as a contribution to dialectical thought. What stands in the way of this is that dialectics tends to be identified either with the geometrized dialectic of Hegel's Science of Logic, or with dialectic as characterized by Friedrich Engels and the Marxists who followed Engels. What has been lost is a broader and more adequate history of dialectics, and the absence of this is largely responsible for the lack of appreciation of natural philosophy and how it has developed.

To begin with it is necessary to appreciate dialectics as it was developed in Ancient Greece, particularly by Plato. Aristotle also utilized a form of dialectical thinking to reason from reputable opinions on any subject matter to reach what he claimed were the first principles for their study. This is too limited. Plato, on the other hand, developed dialectic as a way of questioning to discover the meaning of words, thereby revealing the relationship of these words and their meanings to each other, while giving a place to new conjectures or speculations and the development of radically new ideas and ways of thinking. He is known primarily for the claim that knowledge can only be of the Forms (eidos), although whether these are separate, transcendent entities or omni-temporal aspects of what exists (as Jaakko Hintikka, [55] (p. 67f.) among others, argued) is open to dispute. If the latter, Plato could be regarded as a naturalist as well as a natural philosopher. Heidegger [56] (p. 104) claimed that Plato upheld an older notion of truth as disclosing or revealing, while at the same time elaborating a coherence theory of truth according to which, as Gail Fine summarized,

'... one knows more to the extent that one can explain more: knowledge requires, not a vision, and not some special sort of certainty or infallibility, but sufficiently rich, mutually supporting, explanatory accounts. Knowledge, for Plato, does not proceed piecemeal; to know, one must master a whole field, by interrelating and explaining its diverse elements' [57] (p. 114).

So, dialectics in Plato was a form of reasoning based on asking questions, beginning with discriminating and appreciating relationships between items identified in this way, and then contrasting different perspectives, thereby enabling people to overcome the one-sided thinking that leads to disasters [58]. In the process, new perspectives could be offered to overcome the limitations of those perspectives revealed to be defective. Achieving this required narratives to allow arguments to be 'viewed together' (that is, they are 'synopses'), always situated in contexts, and Plato's dialogues were, as Nietzsche characterized them in The Birth of Tragedy, philosophical novels [59] (xiv, p. 88).

Subsequently, decontextualized propositional thinking came more and more to dominate philosophical thinking, associated with a more domineering orientation to the world. Aristotle was at the starting point of this trend. While Plato placed dialectics above all other studies, denying 
the possibility of placing any other study, including mathematics, above it, Aristotle distinguished demonstrative reasoning from true premises, utilizing syllogisms, from dialectical reasoning and took demonstrative reasoning to be the more important form of reasoning. It should be noted though that even Aristotle's development of formal logic as a logic of classes and class membership was still closely tied to drawing distinctions and to characterizing the essential differences between diverse kinds of beings, and this itself was a contextual, relational form of thinking. Classes are not merely sets, and they can also be implicitly evaluative. To characterize humans as zoon politikon is not only to distinguish humans from other organisms by virtue of all the capacities that are formed by being educated and then participating in a self-governing community, but to distinguish humans who have developed their potential from those who have not, and to evaluate them as superior by virtue of this.

Aristotle did not identify causation with logical necessity, but such an identification resulted from the trajectory of thought begun by the focus on demonstrative reasoning. Formal logic was about reducing reasoning to following explicit rules, and the further development of this conception of reasoning continued through the centuries, culminating in the seventeenth century. Leibniz claimed that since much of human reasoning is just combinatorial operations on characters it can be substantially improved with the help of a mechanical procedure to guide our judgements. To this end, he proposed an algebra of logic that would specify the rules for manipulating logic concepts. This is the project later embraced by Frege, Bertrand Russell and the logical positivists who, with the development of symbolic logic, also attempted to reduce mathematics to logic and set theory. This project, which led to the development of computers and information technology, became so entrenched that until Jaakko Hintikka pointed it out, most analytic philosophers were unaware of what they were assuming or the possibility of according a different status to demonstrative reasoning [60]. It is this form of demonstrative reasoning that came to dominate science, locking in place Newtonian philosophy of nature and assumptions about science and choking off efforts to develop alternative philosophies of nature, fostering both epistemological and ontological reductionism. As Unger and Smolin pointed out, the Newtonian paradigm extrapolates to the whole universe an explanatory strategy which involves distinguishing 'between initial conditions and timeless laws applying within a configuration space demarcated by stipulated initial conditions' [1] (p. 43), with an implicit ambition to provide mathematical equations through which the state of the universe at each instant could be deduced from any earlier or later state [61]. From this perspective, time as temporal becoming is unreal, and it is assumed that apparent diversity such as the existence of sentient organisms can be explained away as appearances generated by the laws characterizing the fundamental components of nature, whether these be particles, fields or strings. Smolin pointed out just how pervasive this paradigm is:

'To use this paradigm, one inputs the space of states, the law, and the initial state, and gets as output the state at any later time. This method is extremely powerful and general, as can be seen from the fact that it characterizes not just Newtonian mechanics, but general relativity, quantum mechanics and field theories, both classical and quantum. It is also the basic framework of computer science and has been used to model biological and social systems' [1] (p. 373).

In the Middle Ages, the words logic and dialectic were treated as synonymous. This did not really change until Kant used the term 'dialectics' and it was taken up by the post-Kantian philosophers. Kant is usually interpreted from the perspective of neo-Kantianism, which developed (initially by Hermann von Helmholtz) to oppose the influence of post-Kantian philosophy, and for this reason, Kant is usually left out of histories of natural philosophy. This is not surprising because Kant, following interpretations by neo-Kantian philosophers, is usually identified with his critical philosophy grappling primarily with epistemological issues, used to deny the possibility of characterizing the world as it is in itself, the noumenal realm. His vastly superior characterization of mind to Descartes or Locke, the role he ascribed to asking questions as necessary for judgements, and his claim to be laying the foundations for superior knowledge in metaphysics, have been almost completely ignored. Also, largely ignored 
until recently for similar reasons have been his defense of a dynamism, the characterization of matter as forces of repulsion and attraction rather than bits of inert matter occupying space, in his Metaphysical Foundations of Natural Science, and his contributions to philosophical biology in his Critique of Judgment [62] (\$65). Recognizing Kant's broader ambitions, what is important for the history of the idea of natural philosophy is the role he accorded to imagination and to 'concepts', and his defense of a constructivist theory of mathematics according to which we know mathematical truths as synthetic a priori because we have constructed our mathematics. On this basis, he argued that we only know what in some sense we have created. It is also important to recognize his efforts to develop a different kind of reasoning, transcendental deductions, to justify synthetic a priori knowledge about the sensible world. Through these he attempted (unsuccessfully) to demonstrate that we have to accept a particular set of concepts if the sensible manifold we experience is to be made intelligible. In conjunction with these supposed transcendental deductions, Kant reintroduced the term dialectics, although following Aristotle rather than Kant, he did not accord dialecticsa central place. What is more important is that, in attempting to give a place to transcendental deductions, synthetic a priori knowledge, and dialectics he highlighted the need for a different kind of reasoning and different kind of knowledge than had come to dominate and still dominates mainstream science.

The post-Kantian tradition of philosophy emerged with those philosophers who embraced Kant's notion of forms of intuition and categories of the understanding as conceptual frameworks, and developed Kant's concept of synthesis, but went beyond Kant to treat synthesis not as the basis for synthetic a priori knowledge but as central to speculation and speculative knowledge. In some cases, they not only accepted but amplified the place accorded by Kant to imagination. However, they claimed that Kant's notion of the noumenal realm was incoherent in terms of what he claimed could be known and, more importantly, they claimed that Kant failed to specify what transcendental deductions are, or to show that the concepts currently dominating science are the only possible coherent concepts. Speculation, by which old concepts could be brought into question and new concepts and conceptual frameworks elaborated, that is, a more creative form of 'synthetic' thinking, was given a central place. The notion of dialectics was taken up to characterize this, interpreted through Plato's philosophy rather than Aristotle's, and then deployed to show how conceptual frameworks emerge, are or can be criticized, improved upon and replaced by better conceptual frameworks. The figures involved in this revival and development of dialectics were J.G. Fichte, Friedrich Schelling, G.W.F. Hegel, and Friedrich Schleiermacher. As far as natural philosophy is concerned, the most important figure is Schelling, a philosopher who, despite being commonly classified as an Idealist, defended natural philosophy (Naturphilosophie) as more fundamental than transcendental philosophy [63] (p. 5), [64]. It is also important to appreciate that Kant himself in his very last unpublished writings appears to have been developing his ideas in precisely the same direction as Schelling, as I have argued elsewhere [65]. Hegel also attempted to advance natural philosophy as part of his Absolute Idealism, but the focus on his work had the effect of discrediting the contributions to natural philosophy of post-Kantian philosophers.

Fichte began the tradition of post-Kantian philosophy and the revival and development of dialectical thinking, although this is not how he characterized it. Criticizing both the notion of the noumenal realm and Kant's supposed transcendental deductions, he was the first philosopher to embrace and defend the notion of 'intellectual intuition', a notion coined by Kant to describe immediate knowledge of oneself as a thing-in-itself in order to reject it as a possibility. Fichte characterized it as experience of reflection on the nature and development of experience and on the generation of concepts, and on the adequacy of concepts used to interpret experience, anticipating both the genetic phenomenology of Husserl's later work, and the genetic epistemology of Jean Piaget. He accorded extended powers of synthesis to intellectual intuition, claiming that Kant's notion of construction could be extended from mathematics to all cognitive development. For Fichte, intellectual intuition is not a faculty of the subject, but is the subject positing itself and its other, coming to know itself and thereby constituting itself in a non-objective manner through mediation of what can be known 
objectively. He argued for the priority of action in the formation of concepts, taking theoretical knowledge of concepts as derivative [66] (pp. $61 \& 256$ ). It is through action that experience, which is first and foremost 'feeling', including feelings of resistance to striving rather than discrete sensations, is constituted as objects, and it is only on reflection that we develop concepts of these objects. However, Fichte later concluded that self-consciousness and free agency are further dependent upon being recognized by and recognizing other finite rational beings as free and ascribing efficacy to them. 'No Thou, no I: no I, no Thou' he proclaimed [66] (p. 172f.).

Kant had argued that some debates in philosophy are irresolvable. These are the antinomies of pure reason, practical reason and taste; for instance, the claim that all composite substances are made of simple parts (thesis) and no composite thing consists of mere simple parts (antithesis), and that to explain appearances there must be a causality through freedom (thesis) and all that happens is determined by the laws of nature (antithesis). Fichte set out to show that through such synthetic thinking it is possible to reconcile these antinomies, and in doing so, achieve higher syntheses. There is no algorithm for solving such problems. Every problem must be dealt with in its own terms, requiring a fresh exercise of imagination in problem solving. This form of synthetic thinking provided him with a way to construct the concepts required to organize experience, achieving self-comprehension in the process. All of this is made possible, Fichte argued, by 'the wonderful power of productive imagination in ourselves' [66] (pp. 112, 185 \& 187). Unlike conceptual analysis, logical inference, or syllogistic reasoning, this 'dialectical' method of derivation is thoroughly synthetic, always involving imagination. Through such thinking, Fichte attempted to establish and justify the forms of intuition and the categories of the understanding without postulating an unknowable thing-in-itself.

\section{Schelling's Dialectics}

It is dialectics as developed by Schelling that provided the forms of thinking required to revive and develop natural philosophy. Schelling took Fichte's work as his point of departure and focused on and developed the notions of synthesis and construction to forge a synthesis of natural philosophy, art, and history. He took over from Fichte the view that the subject is activity that can be appreciated as such through intellectual intuition, that objects of the sensible world can only be understood in relation to the activity of this subject, that conceptual knowledge originates in practical engagement in the sensible world, that there can be and is also an appreciation of other subjects as activities rather than objects, and that the formation of the self-conscious self is the outcome of the limiting of its activity by the world and other subjects. Schelling also took over and further developed Fichte's defense of construction and his genetic, dialectical approach to construction, but instead of seeing the development of cognition only as humans achieving consciousness of their own self-formation, saw it as the process by which nature has come to comprehend itself and its evolution through humanity. He defended an even stronger thesis against Kant's effort in 'The Discipline of Pure Reason' in the Critique of Pure Reason to limit construction to mathematics [67] (A725/B753ff., p. 677ff.), arguing that 'the philosopher looks solely to the act of construction itself, which is an absolutely internal thing' [66] (§4, p. 13). Thought is inherently synthetic, Schelling argued, and begins with genuine opposition either between thought and something opposing it, or other factors within thought. This necessitates a new synthetic moment that can be treated as a product or factor in the next level of development.

Building on Kant's and Fichte's ascription of a central place to imagination in such synthesis and developing Kant's concept of construction and extending Fichte's genetic approach from the development of cognition to the development of the whole of nature, Schelling characterized 'intellectual intuition' as a form of knowledge gained through a reflective and imaginative experimentation and construction by the productive imagination of the sequence of forms produced by the 'Absolute'; that is, the unconditioned totality, the self-organizing universe. Intellectual intuition reproduces in imagination the process by which nature, through limiting its activity, has constructed itself as a diversity of productivities and products, a process of self-construction in which the philosopher in his or her particular situation is participating. In this way, Schelling embraced and 
further radicalized Kant's more radical conjectures: his dynamism, according to which matter is defined by forces of attraction and repulsion and his conception of living organisms put forward in the Critique of Judgment as unities in which the parts are both causes and effects of their forms [62] (p.252), and in doing so, anticipated not only the notion of autopoiesis but hierarchy theory as developed by Pattee, Allen, and Salthe. Referring to this dialectic as the 'standpoint of production' in contrast to the Kantian 'standpoint of reflection', Schelling was concerned not only to show the social conditions for objective knowledge, but the nature of the world that enables it to be known objectively and explained at least partially through Newtonian physics, while questioning the assumptions of Newtonian physics. At the same time, he was concerned to show how the world has produced subjects able to achieve knowledge of it and of themselves, and who could question current assumptions and ways of conceiving the world, and go beyond received knowledge. This was seen to require the development of a new physics which he claimed would reveal the relationship between magnetism, electricity, and light, provide the theoretical foundations for chemistry, justify and advance Kant's conception of life, and provide a new way of understanding human existence. This, in essence, is the whole project of Schelling's Naturphilosophie [68].

As opposed to Hegel's geometrized dialectic of his Science of Logic, Schelling's version of dialectics requires creative imagination and is infused with willing. The production of truth goes beyond abstract logic and is guided by volition. The advance of the dialectic adds something new; it does not simply sublate earlier phases of the dialectic as in Hegel. This notion of dialectics embraces and extends Kant's constructivist account of mathematics to knowledge generally. Dialectical construction assumes a generative order of nature that is ontologically prior to this dialectical production of truth, and is reproduced by this dialectical construction. Such reconstruction enables the universal and the particular, the ideal and the real, to be grasped together.

Through such construction, Schelling characterized the whole of nature as a self-organizing process, showing how it had successively generated opposing forces, apparently inert matter (in which stability is achieved through a balance of opposing forces), organisms which actively maintain their form, inner sense, and sensory objects, intelligence, self-consciousness and human institutions with their history. Nature on this view is the activity of opposing forces of attraction and repulsion, generating one form after another. He argued that 'The whole of Nature, not just part of it, should be equivalent to an ever-becoming product. Nature as a whole must be conceived in constant formation, and everything must engage in that universal process of formation' [68] (p. 28). Inverting Kant's characterization of causality, Schelling argued that mechanical cause-effect relations are abstractions from the reciprocal causation of self-organizing processes. Matter is itself a self-organizing process. While 'matter' emerges through a static balance of opposing forces, living organisms were characterized by Schelling as responding to changes in their environments to maintain their internal equilibrium by forming and reforming themselves, a process in which they resist the dynamics of the rest of nature and impose their own organization. In doing so, they constitute their environments as their worlds and react to these accordingly. While Schelling was centrally concerned with explaining the emergence and evolution of humans, in the end he abandoned the notion that the telos of the entire universe is humanity and its development, allowing the possibility that in the future humans could become extinct.

Like Unger and Smolin, Schelling defended the philosophy of nature as natural history, the study of how matter, time, space, structures, organisms, and human life have emerged and evolved, in doing so, rejecting Kant's denigration of natural history as not a genuine form of knowledge. A rigorously developed history of the cosmos, Earth and life on Earth within which human history can then be situated, Schelling argued, will provide the ultimate framework for understanding nature. 'From now on," Schelling proclaimed, "Science [Wissenschaft], according to the very meaning of the word, is history [Historie]. ... From now on, science will present the development of an actual, living essence' [69] (p. 13). 
Schelling did not believe that this dialectical reconstruction of nature by itself would guarantee the truth of his philosophy of nature, however. Philosophers should develop their own systems, knowing that no system could be final. Dialectics extends from thoughts of individuals to the thoughts of others and to the relationship between philosophies and philosophical systems, and also the findings of empirical and experimental research guided by these systems. Philosophy advances as less perfect forms of philosophy are discarded and their valuable contents assimilated to more perfect forms. A philosophical system should be judged according to its coherence and comprehensiveness, and its capacity to surpass by including more limited philosophical stances. This is revealed by constructing histories of philosophy, and Schelling wrote a history of modern philosophy to this end. These are the ideas revived by Peirce and Whitehead, and then later, by the post-logical positivist philosophers of science, although they were not identified as part of the tradition of dialectical logic.

Recognizing them as such provides the basis for a better appreciation of their contribution to characterizing dialectical reasoning. Peirce's concept of abduction and his characterization of the relationship between abduction, which is a creative interpretant of received signs of objects being studied, deduction where the necessary implications of these interpretants are spelt out and elucidated, and induction which involves posing questions based on such elucidations that can be answered by experience, paving the way for further abduction, is a significant contribution to and clarifies the nature of dialectical thinking. So also is the reciprocal relationship identified by Whitehead between philosophy's quest for global comprehension, and science's quest for certain knowledge through rigorous methods, with each serving as an impetus for revising and developing the other. Whitehead's insight into the importance of co-existing philosophies to illuminate the deficiencies of each and the importance to traditions of inquiry of acknowledging ideas that had been transcended, appreciated by Schelling and cogently argued for by post-positivist philosophers of science, should also be seen as important aspects of dialectical thinking.

Once this tradition of Schellingian dialectics is recognized, it becomes possible to appreciate which were the real contributions of these later thinkers to the tradition of dialectics and natural philosophy, and also to see where forgotten insights and achievements of earlier thinkers need to be recovered.

\section{Phenomenology, Philosophical Biology, and Philosophical Anthropology}

My claim for the continuity of the tradition of natural philosophy, once the crucial role and influence of Schelling is understood, might not seem to fit philosophical biology and philosophical anthropology as major components of natural philosophy. Explicitly formulated as such, these were influenced by Husserl's phenomenology, although disowned by him, and Husserl was mainly influenced by Brentano and Frege. Brentano was highly critical of Kant and called for a return to Aristotle in place of the neo-Kantian call for a return to Kant, and dismissed Fichte, Schelling, and Hegel as 'lacking all value from a scientific point of view' [70] (p. 21). His core concept of intentionality originated in the Aristotelian tradition of philosophy as Aristotle had been interpreted by Aquinas. Frege is often seen as the originator of analytic philosophy and is usually seen as an anti-Kantian philosopher, and certainly anti-post-Kantian. However, Husserl was also influenced by William James and Henri Bergson [71]. James' radical empiricism was partly influenced by Peirce's phenomenology, but really was a revival of Goethe's call for a proper appreciation of all experience [72] (p. 91f.). Peirce characterized himself as a Schellingian of some stripe. Goethe was Schelling's mentor, and had a strong influence on the development of his philosophy of nature. Bergson corresponded with James, and also belonged to a French tradition of thought influenced by Schelling led by Félix Ravaisson (who attended Schelling's lectures) and Émile Boutroux.

The importance of phenomenology was not that it achieved what Husserl aimed at, a rigorous, science based on a presuppositionless method for examining experience providing apodictic knowledge more fundamental than the natural sciences, a goal that Husserl himself acknowledged had failed [73] (p. 389), but that it freed philosophers from the assumptions about experience (and associated conception of humans) foisted on them by philosophers and scientists influenced by 
Descartes, Thomas Hobbes, John Locke, and Isaac Newton. Phenomenology enabled them to appreciate the complexity of experience, of what they experienced and what they are as experiencing beings. It could deal with the temporality of lived experience, with unreflective, pre-predicative experience as well as the way in which concrete and abstract objects are constituted as a temporal process, the experience of being embodied in the life-world and the highest levels of self-conscious reflection. It freed philosophers (most notably, Merleau-Ponty) to appreciate the original global experience of the world that is the background to discriminating and identifying any item of experience, to examine the discriminations that are made and the bases of these discriminations, that is, the essences of any item of experience, and to see these in their various contexts and in relation to each other. It also enabled philosophers to examine why these discriminations were made. In doing so, it forced philosophers to recognize the temporality of all experience and the complexity of this temporality, and to give a place to the experience of subjects as well as of objects, along with other items of experience that could not be objectified.

Phenomenology gained much of its impetus by offering a rigorous approach to studying topics and issues raised by Schelling in his Essay on Freedom and his late Berlin lectures from 1842 onwards. This was the origin of the existentialist movement. Heidegger's hermeneutic phenomenology was closely associated with existentialism, and such hermeneutics was really a revival of themes developed by Herder, Schleiermacher, and Schelling as well as Wilhelm Dilthey. Phenomenology was providing a logic of context and discrimination, despite Husserl's intentions. Husserl's later genetic form of phenomenology, showing how more complex forms of experiencing and thinking develop out of more basic forms of experience, echoed Fichte's study of cognitive development on the basis of which he developed his notion of dialectics. As Merleau-Ponty [74] suggested and put into practice, genetic phenomenology was a significant contribution to and expansion of dialectics, incorporating into it pre-predicative lived experience while facilitating engagement with various specialized inquiries, scientific and nonscientific, while being irreducible to these specialized inquiries.

It was in this way that phenomenology provided the way to develop philosophical biology and philosophical anthropology as contributions to natural philosophy, beginning with the work of Max Scheler [75] and developed by Helmuth Plessner, Arnold Gehlen, Hans Jonas and others, including most recently, Andreas Weber [76]. This in turn engendered a revival of interest in the work on philosophical biology and philosophical anthropology by Kant, Herder, Hegel, Marx, Engels, and George Herbert Mead [53], and more distantly, Aristotle. It enabled philosophers to examine what were the essential features of any living being as these were experienced in the context of other experiences, ultimately the global experience of the being of the world, differentiating such beings from and relating them to nonliving beings in the context of the world. And it enabled them to examine the essential features of humans as opposed to other living beings, giving a place to the various dimensions of human experience associated with subjectivity that cannot be understood through the objectifying approach of science. It is this which differentiates philosophical biology and philosophical anthropology from developments in theoretical biology and the human sciences committed to doing full justice to the distinctive characteristics of life and of humans, and requires that even these more radical forms of science be judged by their capacity to do justice to the insights of philosophical biologists and philosophical anthropologists $[9,53]$. Philosophical biology and philosophical anthropology also reveal the need for a broader natural philosophy challenging mainstream science, a natural philosophy that privileges temporal becoming and accords a place to self-organizing processes, as with process philosophy, as Merleau-Ponty came to appreciate [10].

\section{Contemporary Natural Philosophy as a Coherent Tradition}

Acknowledging the central place of Schelling in the history of natural philosophy, in characterizing natural philosophy, developing a form of reasoning by which it could be advanced, and offering a particular philosophy of nature, provides the basis for recognizing natural philosophy as a discourse which is a coherent tradition, although not properly recognizing itself or being recognized by others 
as such and therefore somewhat fragmented. This enables us to see natural philosophy as something different from science and mathematics with a different kind of rationality and different and more inclusive criteria for judging progress, and that natural philosophy, while being distinct from science, is essential to the progress of science. It also provides the basis for a better understanding of the history of science and, thereby, much of the confusion in how current science is understood where advances based on the influence of Schelling continue to be interpreted through Newtonian assumptions that Schelling rejected.

Despite the marginalization of natural philosophy and dialectics in philosophy, most of the major advances in science over the last century and a half have been inspired directly or indirectly by the Schellingian tradition of Naturphilosophie $[29,64,77,78]$. Even many of the most important advances in mathematics on which current science is based were inspired by Schelling's call for new developments in mathematics adequate to a dynamic nature, mainly through his influence on Justus and then Hermann Grassmann [79,80]. In developing his extension theory which he offered as a keystone to the entire structure of mathematics, Hermann Grassmann invented linear and multilinear algebra and multidimensional space and foreshadowed the development of vector calculus, vector algebra, exterior algebra, and Clifford algebra. He also anticipated to some extent the development of category theory, which, through the work of Robert Rosen and Andrée Ehresmann, has led to new efforts to provide mathematical models adequate to life [80,81]. Schelling was the first to suggest that electricity, magnetism, and light were associated [82] and could be understood through the dynamism he embraced and developed. Schelling was then a direct influence on Hans Christian Oersted, the first scientist to show a direct relationship between electricity and magnetism. This tradition of dynamism, and especially the contribution to it of Schelling, was embraced in Britain by Coleridge and his circle, which included the mathematician William Hamilton and Humphrey Davey. Faraday's work and his notion of fields were enthusiastically supported by this circle, along with the Oxford philosopher William Whewell who coined many of the terms utilized and incorporated by Faraday into physics (for instance, 'anode', 'cathode', 'ion', and 'dialectric'). Faraday's work, including his development of field theory, was hailed by Schelling himself as the fulfilment of his philosophy of nature, and this was reported to Faraday by Whewell [83] (p. 296f.). Naturphilosophie inspired the first law of thermodynamics, that energy is conserved, leading to claims by some natural philosophers, the energeticists, that energy should replace matter as the basic concept of science [84] (p. 301). This included Aleksandr Bogdanov whose work on tektology, the study of organization, was a major influence on the development of general systems theory [85]. Insofar as chemistry is based on the notion of chemicals existing as balances of opposing forces (valence), it also manifests the influence of Schelling's Naturphilosophie [84] (p. 321). Darwin's evolutionary theory was strongly influenced by Alexander von Humboldt, a friend of Schelling and an admirer of his natural philosophy [86] (ch. 14). Building on Kant's conception of living organisms, Schelling anticipated Jacob von Uexküll's characterization of organisms as defining their environments as their worlds and the more recent notion of autopoiesis.

More broadly, the whole tradition of process philosophy as developed through Peirce, James, Bergson, and Whitehead and those they influenced, by virtue of the philosophers and mathematicians who influenced these thinkers, should be seen as part of the tradition inspired by Schelling, despite Whitehead being influenced only indirectly by Schelling and claiming that he was returning to pre-Kantian forms of philosophizing [65]. Most natural philosophy since Whitehead can be seen as developing the tradition of process philosophy or in some way aligned with it, and Unger and Smolin's work, defending temporality and creative emergence, accords with and is really a contribution to process philosophy.

As Unger and Smolin noted, most scientists put forward their ideas on natural philosophy in books written to popularize their work. They are very often influenced by this tradition of natural philosophy, and a few have engaged with the work of natural philosophers and made significant contributions to natural philosophy. David Bohm and Ilya Prigogine are obvious examples. The biosemioticians have 
revived Peirce's natural philosophy, a form of process philosophy strongly influenced by Schelling [64], and Jesper Hoffmeyer's popularization of biosemiotics in his book Signs of Meaning in the Universe [87] was a significant contribution to natural philosophy entirely in the tradition of Schellingian philosophy of nature. This work has had a significant influence on some biologists and also on other disciplines. Biosemiotics has provided a rigorous foundation for reviving, defending, and further developing both philosophical biology and philosophical anthropology [53,76], which, in turn, challenges and calls for a redirection of biology and human sciences generally.

Other work in philosophical biology and philosophical anthropology is less directly influenced by Schelling and the tradition of Naturphilosophie. The more immediate influence was Husserlian phenomenology. However, once developed, earlier and often more profound work in philosophical biology and philosophical anthropology could be recovered and integrated with this later work, most importantly, Kant's and Schelling's efforts to characterize life and the characterization of humans by Hegel. Merleau-Ponty's philosophy exemplifies such efforts. However, there were other developments in philosophical biology and philosophical anthropology not labelled as such that have advanced these areas of study. This includes more recent efforts to naturalize phenomenology inspired by Merleau-Ponty and Francesco Varela [61], and the work of the earlier philosophical anthropologists such as Herder and Hegel. Harré's work on providing new foundations for psychology, work associated with hierarchy theory and Peircian and non-Peircian biosemiotics, and the work of various cross disciplinary thinkers such as Terrence Deacon and Andreas Weber, are also contributions to philosophical biology and philosophical anthropology.

Complexity theory, insofar as it is genuinely opposed to reductionism, as developed by Prigogine, Howard Pattee, Brian Goodwin, Stuart Kauffman, and Robert Ulanowicz, should also be seen as another triumph of the tradition of Naturphilosophie, although only very indirectly influenced by it [80]. This includes Alicia Juarrero's work, Dynamics in Action: Intentional Behaviour as a Complex System [88], and work on anticipatory systems, most importantly, the work of Robert Rosen and those he influenced. Rosen's work, grappling with the problem of modelling life itself and developing new forms of mathematics adequate to this, and his claim that biology rather than physics should become the reference point for defining science and its goals, is a major contribution to natural philosophy providing further support for Schelling's efforts to overcome the Newtonian tradition of science [80,89-91].

All such work is now being brought to bear on what is claimed by more conventional philosophers to be the hard problem of accounting for consciousness, much of it associated with the development of neuroscience. This has attracted a number of radical scientists who have written popularizations of their work and in doing so have contributed to natural philosophy [92-94]. Here more than anywhere else the fragmentation of ideas in this area is damaging not only the advance of science, but of society more generally by allowing fundamentally defective characterizations of humans in the human sciences, particularly in economics and psychology, to dominate the cultures of nations. Seeing the effort to understand the place of sentient organisms and humans capable of understanding themselves and their place within nature as the core problem uniting the whole tradition of natural philosophy since Schelling, and seeing the rationality underpinning and required to further develop this tradition as dialectical reason, should provide the means to overcome this fragmentation.

\section{Conclusions: Creating the Future}

It should now be evident that Unger and Smolin are continuing the modern tradition of natural philosophy that goes back to Schelling, grappling with the problem of how sentience can have emerged in the evolution of nature [1] (p. 480ff.). It is of major significance because the views defended are responses to the failures of advanced theoretical physics where assumptions deriving from Newtonian science are most deeply entrenched, and what they defended is an important contribution to advancing the Schellingian tradition of thought. They are reconceiving the very nature of science and its place in 
culture and society, and this has great relevance for confronting the cultural deficiencies of our present civilization. Their work can thus be evaluated in relation to this tradition.

To begin with, in their defense of the reasoning and claims to knowledge of natural philosophy and the significance of this knowledge, they have contributed to dialectical thinking [1] (p. 76ff.). The new form of science influenced by a revived natural philosophy would have several features:

'[A] more ample dialectic among theories, instruments, observations, and experiments than is ordinarily practiced. Another is the investigation of problems that require crossing boundaries among fields as well as among the methods around which each field is organized. Yet another is the deliberate and explicit mixing of higher-order and first-order discourse. Viewed in this light, natural philosophy works to overcome the contrast between normal and revolutionary science' $[1]$ (p. 82).

Natural philosophy was defended by them as a broad discourse which could engage with science, criticize it, and open new directions for research, changing the agenda of scientific research. With the revival of natural philosophy, it would be a recognized part of everyday science to identify presuppositions and consider replacing these one by one. This would involve maintaining a distinction between what science has discovered and interpretations of these discoveries, so that these discoveries could be reinterpreted. This largely accords with the discourse on natural philosophy defended by Schelling as natural philosophy, speculative physics, and natural history, and defended by Whitehead as speculative philosophy [26], but puts the ideas developed by these earlier thinkers in focus in relation to very recent science.

The most important component of the natural philosophy defended by Unger and Smolin involves reconceiving the role of mathematics in science, downgrading it and subordinating it to natural history. There have been several precursors to this, beginning with Schelling himself in opposing Kant's claim that there is only as much science as there is mathematics and in defending natural history against Kant. Grassmann accepted that, in the quest to understand nature, mathematics and the reasoning associated with it has its limits, as did Peirce and Whitehead. This was the basis of Peirce's natural philosophy privileging habits and semiosis, giving a place to the creativity that has generated diversity and Whitehead's natural philosophy giving a central place to process and creativity. More recently, theoretical scientists have pointed to the inevitable limitations of mathematics, including Prigogine, Robert Rosen, Salthe, Hoffmeyer, and Kauffman. However, most of these have been theoretical biologists, and even radical physicists such as Roger Penrose have been loath to countenance rejecting the Pythagoreanism of the Newtonian tradition of science. For a leading theoretical physicist to contribute to this debate on the side of those questioning the defining role of mathematics in science is itself a major event. Furthermore, Smolin offers an original way of characterizing the nature and role of mathematics in science that can be seen to accord with Schelling's natural philosophy [1] (p. 422ff.).

Smolin argues that new structures that can be characterized mathematically emerge into existence, and that mathematics itself is evoked in this way. Just as chess was an invention that, once evoked with its rules of play, made possible the exploration of a vast landscape of possibilities, mathematical structures are evoked, creating vast landscapes of possibilities that can be explored. These possibilities are not arbitrary but are objective properties of these mathematical structures. The bulk of mathematics consists in the elaboration of four concepts: number, geometry, algebra, and logic. Our knowledge of number and geometry apply to the world because they were developed through studying the world, that itself evolved by generating new structures. Number captures the fact that the world consists of denumerable objects that can be counted, while geometry captures the fact that these objects take up space and form shapes. Algebra captures the fact that these numbers can be transformed. Logic captures the fact that we can reason and draw conclusions about the first three concepts. According to current physics and cosmology, there was a stage in the universe where there were vacuum states of quantum fields without space and without elementary particles, and so no denumerable objects. We ourselves are part of a world where space and denumerable objects do 
exist, and our arithmetic and geometry, which are the foundation for evoking further developments in mathematics, were elaborated because the relations of geometry and number had emerged in nature. Later developments in mathematics, for instance through axiomatization of geometry, making possible new kinds of geometry, are evoked through the invention of novel ways of thinking. New forms of mathematics have been evoked through the invention of algebra, then through the formalization of logic, and then through the development of group theory and topology facilitating the study of symmetries. Although Smolin does not allude to this, at present, category theory is evoking new developments in mathematics more adequate to life and consciousness [81,91]. However, possibilities evoked through further developments of mathematics might never be realized, and there are structures and possibilities that cannot be grasped through mathematics. There is a potential infinity of formal axiomatic systems that can be evoked, but only a very small subset of these provide partial mirrors or models of nature, and the elaboration and exploration of these systems is no substitute for empirical research and must recognize structures and possibilities that cannot be modelled mathematically. This view of mathematics, Smolin claims, transcends the opposition between constructionism and Platonism, since there is a constructive component and such construction can go on indefinitely, but the possibilities are objectively there, and in the case of number and geometry and a small subset of the axiomatic systems that have been evoked, these possibilities have emerged in nature.

This view of mathematics involves abandoning the quest for the discovery of a timeless realm of mathematical truths modelling the entire universe. Just as geometrical possibilities only emerged with the emergence of space and arithmetic possibilities only emerged with denumerable particles, the applicability of mathematics is dependent on which stable structures have emerged with the evolution of the universe. Unger and Smolin have embraced this notion of evolution from biology and, along with it, the notion of co-evolution from ecology. The mathematical described laws of nature and the possibilities that can be pre-stated through them co-evolved with these structures which exist in the process of realizing these possibilities. However, in doing so, these structures can be transformed, and new structures created, creating new possibilities that did not pre-exist these new structures. This can be seen in biology and the human sciences, where the structures clearly have emerged and are clearly mutable. The laws of economics formulated by economic theory could only be evoked when there were people able to make monetary exchanges. But the nature of these exchanges has changed with new institutions and, as Unger pointed out, economic theory in its quest for timeless truths which do not consider the mutability of institutions has distorted our understanding of the economy and its possibilities [1] (p. 339ff.). Associated with this co-evolution, the so-called constants of physics along with physical laws and symmetries should be seen as only relatively enduring and could be changing with the evolution of the universe. This claim is central to Smolin's efforts to advance cosmological theory in new directions.

All this accords with the Schellingian tradition of natural philosophy and the science that it has engendered, including taking comprehension of the self-organization of life as characterized by Kant in the Critique of Judgment as the reference point for defining science rather than physics, and then characterizing his natural philosophy as a speculative physics designed to replace Newtonian physics [68] (p. 195). The idea of space and then denumerable objects emerging is entirely consistent with Schelling's philosophy where his notion of intellectual intuition was characterized as effectively the reconstruction in thought of the necessary stages in the creative construction of the universe leading up to the development of humanity and individuals through whom the universe is becoming conscious of itself as constructive activity. On this view, instead of treating human consciousness as outside the world it is studying, life and humanity, mathematics and science must be seen as having in some sense co-evolved with the structures of the universe, and it is for this reason that the development of arithmetic and geometry, and then later forms of mathematics that have modelled these structures, is possible. Humans are part of the universe, and so their development of mathematics and science is part of the development of the universe and influences which possibilities will be identified and realized. In the case of the natural sciences, this facilitates the development of new technologies. In the 
case of the human sciences, this facilitates new relations between people and between humans and the rest of nature, and new social structures based on these relations facilitating exploration of their possibilities. Defective science does not merely limit what possibilities can be realized but can be destructive of structures and their possibilities. Unger points this out in his analysis of economic theory and its failures brought about by its quest for eternally true mathematical models and its blindness to institutions and their transformations.

By invoking co-evolution, Unger and Smolin are not only aligning their work with that of post-reductionist biologists, but with ecology. The notion of co-evolution was developed in the process of taking ecology seriously in evolutionary theory and acknowledging the importance of symbiosis and the creativity generated through the balancing of opposing forces. Robert Ulanowicz has argued that it is ecology rather than just biology that should be taken as the reference point for defining science and charting new directions for it, not only in biology but even in physics, overcoming the conceptual logjams that are presently afflicting science generally [95] (p. 6), [96]. These claims are supported by Andreas Weber [76] and Gare [5]. Ecology provides a focus for integrating all the diverse developments in the Schellingian tradition of natural philosophy and science, including energetics, the theory of fields, hierarchy theory, and biosemiotics (as ecosemiotics), and it could be argued that ecology provides the best basis for evoking new advances in Schellingian philosophy of nature and Schellingian science. Ecology is being embraced in biology where organisms are now being characterized as highly integrated ecosystems and Unger and Smolin's work vindicates Ulanowicz's claim that ideas being developed in ecology could facilitate overcoming the roadblocks in physics.

When the whole tradition of natural philosophy is revealed, it becomes clear that it has been more than just guiding and facilitating the development of science. Reflecting on and questioning the place of science in culture, society, and civilization, natural philosophy is central to the dynamics of culture and civilization [97]. It is through natural philosophy that we define our place in the cosmos, and this underpins all other human endeavors. Baconian, Galilean, Cartesian, and Newtonian assumptions dominating science associated with their philosophies of nature are largely responsible for seeing science primarily as a means of achieving control over the world, including other people insofar as the human sciences embrace these assumptions. As Heidegger argued, nature and then people are enframed as standing reserves to be controlled and exploited [98] (p. 21). The quest for control is responsible for astonishing technological achievements that are why in one form another European civilization came to dominate the world. However, these very achievements have created a nihilistic culture and a global ecological crisis which threatens the future of civilization, and possibly humanity itself [41]. It is necessary to evoke a new kind of science and to reformulate all old science to understand this in all its dimensions and to open up different possibilities for the future, elevating ecology to a dominant position in science, replacing mainstream economics by ecological economics and mainstream sociology by human ecology, defending the humanities and reformulating history so that it takes into account geography and ecology, and then embodying this new conception of the world in our culture and institutions. This is required to create an ecologically sustainable civilization, or as radical Chinese environmentalists have argued for, an ecological civilization [5]. At present, this provides the most important reason for promoting natural philosophy [5] (97). Unger and Smolin's work, by defending the importance of natural philosophy, redefining the goal of science, challenging the pre-eminence of mathematics over history in cosmology to accord a place to temporality, creativity and qualia in nature, is a significant contribution to realizing this goal.

Funding: This research received no external funding.

Conflicts of Interest: The authors declare no conflict of interest. 


\section{References}

1. Unger, R.M.; Smolin, L. The Singular Universe: The Reality of Time; Cambridge University Press: Cambridge, UK, 2015.

2. Randall, J.H., Jr. Aristotle; Columbia University Press: New York, NY, USA, 1960.

3. Aristotle. Metaphysics; Hope, R., Translator; The University of Michigan Press: Ann Arbor, MI, USA, 1960.

4. Benardete, J. Metaphysics: The Logical Approach; Oxford University Press: Oxford, UK, 1989.

5. Gare, A. The Philosophical Foundations of Ecological Civilization: A Manifesto for the Future; Routledge: London, UK, 2017.

6. Lindberg, D.C.; Westman, R.S. (Eds.) Reappraisals of the Scientific Revolution; Cambridge University Press: Cambridge, UK; New York, NY, USA, 1990.

7. Smolin, L. The Trouble with Physics; Houghton Mifflin: Boston, MA, USA, 2006.

8. Grene, M. Approaches to Philosophical Biology; Basic Books: New York, NY, USA, 1968.

9. Gare, A. Approaches to the Question "What is Life?": Reconciling Theoretical Biology with Philosophical Biology. Cosmos Hist. 2008, 4, 53-77.

10. Merleau-Ponty, M. Nature: Course Notes from the College de France; Robert, V., Translator; Northwestern University Press: Evanston, IL, USA, 2003.

11. Varela, F.J.; Thompson, E.; Rosch, E. The Embodied Mind: Cognitive Science and Human Experience; MIT Press: Cambridge, MA, USA, 1993.

12. Petitot, J.; Varela, F.J.; Pachoud, B.; Roy, J.M. Naturalizing Phenomenology: Issues in Contemporary Phenomenology and Cognitive Science; Stanford University Press: Stanford, CA, USA, 1999.

13. Simeonov, P.L.; Gare, A.; Rosen, S.M.; Noble, D. Focussed Issue: Integral Biomathics: Life Sciences, Mathematics, and Phenomenological Philosophy. Prog. Biophys. Mol. Biol. 2015, 119, 208-217. [CrossRef] [PubMed]

14. Harré, R. The Principles of Scientific Thinking; University of Chicago Press: Chicago, IL, USA, 1970.

15. Harré, R.; Madden, E.H. Causal Powers: A Theory of Natural Necessity; Blackwell: Oxford, UK, 1975.

16. Harré, R. Personal Being: A Theory of Individual Psychology; Blackwell: Oxford, UK, 1983.

17. Harré, R. Social Being, 2nd ed.; Blackwell: Oxford, UK, 1993.

18. Čapek, M. Bergson and Modern Physics; Reidel: Dordrecht, The Netherlands, 1971.

19. Leclerc, I. Whitehead's Metaphysics; University Press of America: Lanham, MD, USA, 1986.

20. Leclerc, I. The Nature of Physical Existence; George Allen \& Unwin: London, UK, 1972.

21. Leclerc, I. The Philosophy of Nature; The Catholic University of America Press: Washington, DC, USA, 1986.

22. Prigogine, I. From Being to Becoming: Time and Complexity in the Physical Sciences; W.H. Freeman: San Francisco, CA, USA, 1980.

23. Prigogine, I.; Stengers, I. Order Out of Chaos; Bantam Books: New York, NY, USA, 1984.

24. Bogaard, P.A.; Treash, G. Metaphysics as Foundation: Essays in Honour of Ivor Leclerc; S.U.N.Y. Press: Albany, NY, USA, 1993.

25. Rescher, N. Process Metaphysics: An Introduction to Process Philosophy; SUNY Press: Albany, NY, USA, 1996.

26. Gare, A. Speculative Metaphysics and the Future of Philosophy: The Contemporary Relevance of Whitehead's Defense of Speculative Metaphysics. Australas. J. Philos. 1999, 77, 127-145. [CrossRef]

27. Waddington, C.H. (Ed.) Towards a Theoretical Biology; Edinburgh University Press: Edinburgh, UK, 1968-1972; Volume 4.

28. Salthe, S.N. Evolving Hierarchical Systems; Columba University Press: New York, NY, USA, 1985.

29. Salthe, S.N. Development and Evolution: Complexity and Change in Biology; MIT Press: Cambridge, MA, USA, 1993.

30. Salthe, S. The natural philosophy of ecology: Developmental systems ecology. Ecol. Complex. 2005, 2, 1-19.

31. Pattee, H.H.; Raczaszek-Leonardi, J. Laws, Language and Life: Howard Pattee's Classic Papers on the Physics of Symbols with Contemporary Commentary; Springer: Dordrecht, The Netherlands, 2012.

32. Cobb, J.B., Jr.; Griffin, D.R. (Eds.) Mind in Nature: The Interface of Science and Philosophy; University Press of America: Washington, DC, USA, 1978.

33. Griffin, D.R. (Ed.) Physics and the Ultimate Significance of Time: Bohm, Prigogine and Process Philosophy; SUNY Press: Albany, NY, USA, 1986.

34. Eastman, T.E.; Keeton, H. (Eds.) Physics and Whitehead: Quantum, Process, and Experience; SUNY Press: Albany, NY, USA, 2004. 
35. Henning, B.G.; Scarfe, A.C. (Eds.) Beyond Mechanism: Putting Life Back into Biology; Lexington Books: Lanham, MD, USA, 2013.

36. Favareau, D. (Ed.) Essential Readings in Biosemiotics: Anthology and Commentary; Springer: Dordrecht, The Netherlands, 2010.

37. Brier, S. Cybersemiotics: Why Information Is Not Enough; University of Toronto Press: Toronto, ON, Canada, 2010.

38. Bengt-Pedersen, C.; Thomassen, N. (Eds.) Nature and Lifeworld: Theoretical and Practical Metaphysics; Odense University Press: Odense, Denmark, 1998.

39. Andersen, P.B.; Emmeche, C.; Finnemann, N.O.; Christiansen, P.V. (Eds.) Downward Causation: Minds, Bodies and Matter; Aarhus Uni. Press: Langelandsgade, Denmark, 2000.

40. Seibt, J. (Ed.) Process Theories: Crossdisciplinary Studies in Dynamic Categories; Kluwer: Dordrecht, The Netherlands, 2003.

41. Gare, A. Nihilism Inc.: Environmental Destruction and the Metaphysics of Sustainability; Eco-Logical Press: Sydney, Australia, 1996.

42. Whitehead, A.N. Modes of Thought; The Free Press: New York, NY, USA, 1938.

43. Charlton, B.G. Not Even Trying: The Corruption of Real Science; University of Buckingham Press: Buckingham, UK, 2012.

44. Baynes, K.; Bohman, J.; McCarthy, T. (Eds.) After Philosophy: End or Transformation? MIT Press: Cambridge, MA, USA, 1988.

45. Whitehead, A.N. Adventures of Ideas; The Free Press: New York, NY, USA, 1993.

46. Whitehead, A.N. Process and Reality [1929]; Griffin, D.R., Sherburne, D.W., Eds.; Corrected Edition; Free Press: New York, NY, USA, 1978.

47. Whitehead, A.N. The Function of Reason; Princeton University Press: Princeton, NJ, USA, 1929.

48. Kann, C. Renewing Speculation: The Systematic Aim of Whitehead's Philosophical Cosmology. In Beyond Metaphysics? Explorations in Alfred North Whitehead's Late Thought; Faber, R., Henning, B.G., Combs, C., Eds.; Rodopi: Amsterdam, The Netherlands, 2010; pp. 27-44, ISBN 978-90-420-3122-7.

49. MacIntyre, A. Epistemological Crises, Dramatic Narrative and the Philosophy of Science. Monist 1977, 60, 453-472. [CrossRef]

50. Whitehead, A.N. Science and the Modern World; Cambridge University Press: Cambridge, UK, 1932.

51. Clark, C. Knowing, Doing, and Being: New Foundations for Consciousness Studies; Imprint Academia: Exeter, UK, 2013.

52. Brenner, J.E. The Philosophical Logic of Stéphano Lupasco (1900-1988). Log. Log. Philos. 2010, 19, $243-285$. [CrossRef]

53. Gare, A. Philosophical Anthropology, Ethics and Political Philosophy in an Age of Impending Catastrophe. Cosmos Hist. 2009, 5, 264-286.

54. Livingston, P.M. The Politics of Logic: Badiou, Wittgenstein, and the Consequences of Formalism; Routledge: London, UK, 2012.

55. Hintikka, J. Knowledge and the Known: Historical Perspectives in Epistemology; Reidel: Dordrecht, The Netherlands, 1974.

56. Heidegger, M. The Essence of Truth; Sadler, T., Translator; Continuum: London, UK, 2002.

57. Fine, G. Knowledge and belief in Republic v-vii. In Epistemology; Everson, S., Ed.; Cambridge University Press: Cambridge, UK, 1990; pp. 85-115.

58. Lamprecht, S.P. Metaphysics: Its Function, Consequences, and Criteria. J. Philos. 1946, 43, 393-401. [CrossRef]

59. Nietzsche, F. The Birth of Tragedy. In The Birth of Tragedy and The Genealogy of Morals; Nietzsche, F., Ed.; Golffing, F., Translator; Anchor Books: New York, NY, USA, 1956.

60. Hintikka, J. Language as Calculus VS. Language as Universal Medium; Kluwer: Dordrecht, The Netherlands, 1989.

61. Kauffman, S.; Gare, A. Beyond Descartes and Newton: Recovering life and humanity. Prog. Biophys. Mol. Biol. 2015, 119, 219-244. [CrossRef] [PubMed]

62. Kant, I. Critique of Judgment; Pluhar, W.S., Translator; Hackett: Indianapolis, IN, USA, 1987.

63. Schelling, F.W.J. System of Transcendental Idealism [1800]; Heath, P., Translator; University Press of Virginia: Charlottesville, VA, USA, 1978.

64. Gare, A. From Kant to Schelling to Process Metaphysics: On the Way to Ecological Civilization. Cosmos Hist. 2011, 7, 26-69. 
65. Gare, A. From Kant to Schelling: The Subject, the Object, and Life. In Objectivity after Kant; Van de Vijver, G., Demarest, B., Eds.; Georg Olms Verlag: Hildescheim, Germany, 2013; pp. 129-140.

66. Fichte, J.G. The Science of Knowledge; Heath, P.; Lachs, J., Translators; Cambridge University Press: Cambridge, UK, 1982.

67. Kant, I. Critique of Pure Reason; Pluhar, W.S., Translator; Hackett: Indianapolis, IN, USA, 1996.

68. Schelling, F.W.J. First Outline of a System of the Philosophy of Nature [1799]; Peterson, K.R., Translator; SUNY Press: Albany, NY, USA, 2004.

69. Schelling, F.W.J.; Žižek, S. Ages of the World [1813]. In The Abyss of Freedom/Ages of the World; Norman, J., Translator; Second Draft; The University of Michigan Press: Ann Arbor, MI, USA, 1977.

70. George, R.; Koehn, G. Brentano's Relation to Aristotle. In The Cambridge Companion to Brentano; Jacquette, D., Ed.; Cambridge University Press: Cambridge, UK, 2004; Chapter 2.

71. Edie, J.M. William James and Phenomenology; Indiana University Press: Bloomington/Indianapolis, IN, USA, 1987.

72. Richardson, R.D. William James. In the Maelstrom of American Modernism; Houghton Mifflin Company: Boston/New York, NY, USA, 2006.

73. Husserl, E. The Crisis of European Sciences and Transcendental Phenomenology; Northwestern University Press: Evanston, IL, USA, 1979.

74. Merleau-Ponty, M. The Philosopher and Sociology. In Signs; McLeary, R.C., Translator; Northwestern University Press: Evanston, IL, USA, 1964; Chapter 3.

75. Scheler, M. Man's Place in Nature; Meyerhoff, H., Translator; Beacon Press: Boston, MA, USA, 1961.

76. Weber, A. Biopoetics: Towards an Existential Ecology; Springer: Dordrecht, The Netherlands, 2016.

77. Esposito, J.L. Schelling's Idealism and Philosophy of Nature; Bucknell University Press: Lewisburg, PA, USA, 1977.

78. Heuser-Kessler, M. Die Produktivität der Natur: Schellings Naturphilosophie und das neue Paradigma der Selbsorganization in den Naturwissenschaften; Duncker \& Humblot: Berlin, Germany, 1986.

79. Heuser, M. Geometrical Product-Exponentiation-Evolution. Justus Günter Grassmann and Dynamist Naturphilosophie. In Hermann Günter Grassmann (1809-1877): Visionary Mathematician, Scientist and Neohumanist Scholar; Schubring, G., Ed.; Kluwer: Dordrecht, The Netherlands, 1996; pp. 47-58.

80. Gare, A. Overcoming the Newtonian paradigm: The unfinished project of theoretical biology from a Schellingian perspective. Prog. Biophys. Mol. Biol. 2013, 113, 5-24. [CrossRef] [PubMed]

81. Simeonov, P.L.; Smith, L.L.; Ehresmann, A.C. (Eds.) Integral Biomathics: Tracing the Road to Reality; Springer: Berlin, Germany, 2012.

82. Amora, K.C. Schelling and the Dual Nature of Light. Philósophos 2008, 1, 109-124.

83. Whewell, W. Letter 836-William Whewell to Faraday, 23rd November, 1835. In The Correspondence of Michael Faraday, Volume 2: 1832-1840; James, F.A.J.L., Ed.; The Institution of Electrical Engineers: London, UK, 1993; pp. 296-297.

84. Gower, B. Speculation in Physics: The History and Practice of Naturphilosophie. Stud. Hist. Philos. Sci. 1973, 4, 301-356. [CrossRef]

85. Gare, A. Aleksandr Bogdanov's History, Sociology and Philosophy of Science. Stud. Hist. Philos. Sci. 2000, 31, 231-248. [CrossRef]

86. Richards, R.J. The Romantic Conception of Life: Science and Philosophy in the Age of Goethe; University of Chicago Press: Chicago, IL, USA, 2002.

87. Hoffmeyer, J. Signs of Meaning in the Universe; Haveland, B.J., Translator; Indiana University Press: Bloomington, IN, USA, 1993.

88. Juarrero, A. Dynamics in Action: Intentional Behavior as a Complex System; MIT Press: Cambridge, UK, 2002.

89. Rosen, R. Life Itself: A Comprehensive Inquiry into the Nature, Origin, and Fabrication of Life; Columbia University Press: New York, NY, USA, 1991.

90. Rosen, R. Essays on Life Itself; Columbia University Press: New York, NY, USA, 2002.

91. Rosen, R. Anticipatory Systems: Philosophical, Mathematical and Methodological Foundations, 2nd ed.; Springer: New York, NY, USA, 2012.

92. Freeman, W.J. How Brains Make up Their Minds; Weidenfeld: London, UK, 1999.

93. Edelman, G.M. Second Nature: Brain Science and Human Knowledge; Yale University Press: New Haven, CT, USA, 2006.

94. Gare, A. Chreods, Homeorhesis and Biofields: Find the Right Path for Science through Daoism. Prog. Biophys. Mol. Biol. 2017, 131, 61-91. [CrossRef] [PubMed]

95. Ulanowicz, R.E. Ecology: The Ascendent Perspective; Columbia University Press: New York, NY, USA, 1997. 
96. Ulanowicz, R.E. A Third Window: Natural Life beyond Newton and Darwin; Templeton Foundation Press: West Conschohocken, PA, USA, 2009.

97. Gare, A.; Hudson, W. The Challenge of a New Naturalism. In For a New Naturalism; Gare, A., Hudson, W., Eds.; Telos Press: Candor, NY, USA, 2017.

98. Heidegger, M. The Question Concerning Technology. In The Question Concerning Technology and Other Essays; Lovitt, W., Ed. \& Translator; Harper Torchbooks: New York, NY, USA, 1977; pp. 3-35. 